\begin{tabular}{|l|l|}
\hline $\begin{array}{l}\text { 2. To: (Receiving Organization) } \\
\text { DISTRIBUTION }\end{array}$ & $\begin{array}{l}\text { 3. From: (Originating Organization) } \\
\text { Site Systems Engineering/Systems } \\
\text { Integration }\end{array}$ \\
\hline 5. Proj./Prog./Dept./Div.: & $\begin{array}{l}\text { 6. Design Authority/Design Agent/Cog. } \\
\text { Engr.: }\end{array}$ \\
$\begin{array}{l}\text { Hanford Site Technical Database } \\
\text { (HSTD)/Site Systems } \\
\text { Engineering/Systems Integration }\end{array}$ & P. A. Baynes/A. K. Lee/N. J. Graves \\
\hline 8. Originator Remark: & \\
\hline
\end{tabular}

ATTACHED IS THE COMPLETED SOFTWARE CONFIGURATION

MANAGEMENT PLAN FOR THE HANFORD SITE TECHNICAL DATABASE

11. Receiver Remarks: 11A. Design Baseline Document? [] Yes [X] No
4. Related EDT No::

N/A

7. Purchase Order No:

NIA

9. Equip./Component No.

N/A

10. System/BIdg./Facility:

HSTD/2420 Stevens Cntr

12. Major Assm. Dwg. No.:

N/A

13. Fermit/Permit Application No:

N/A

14. Required Response Date:

N/A

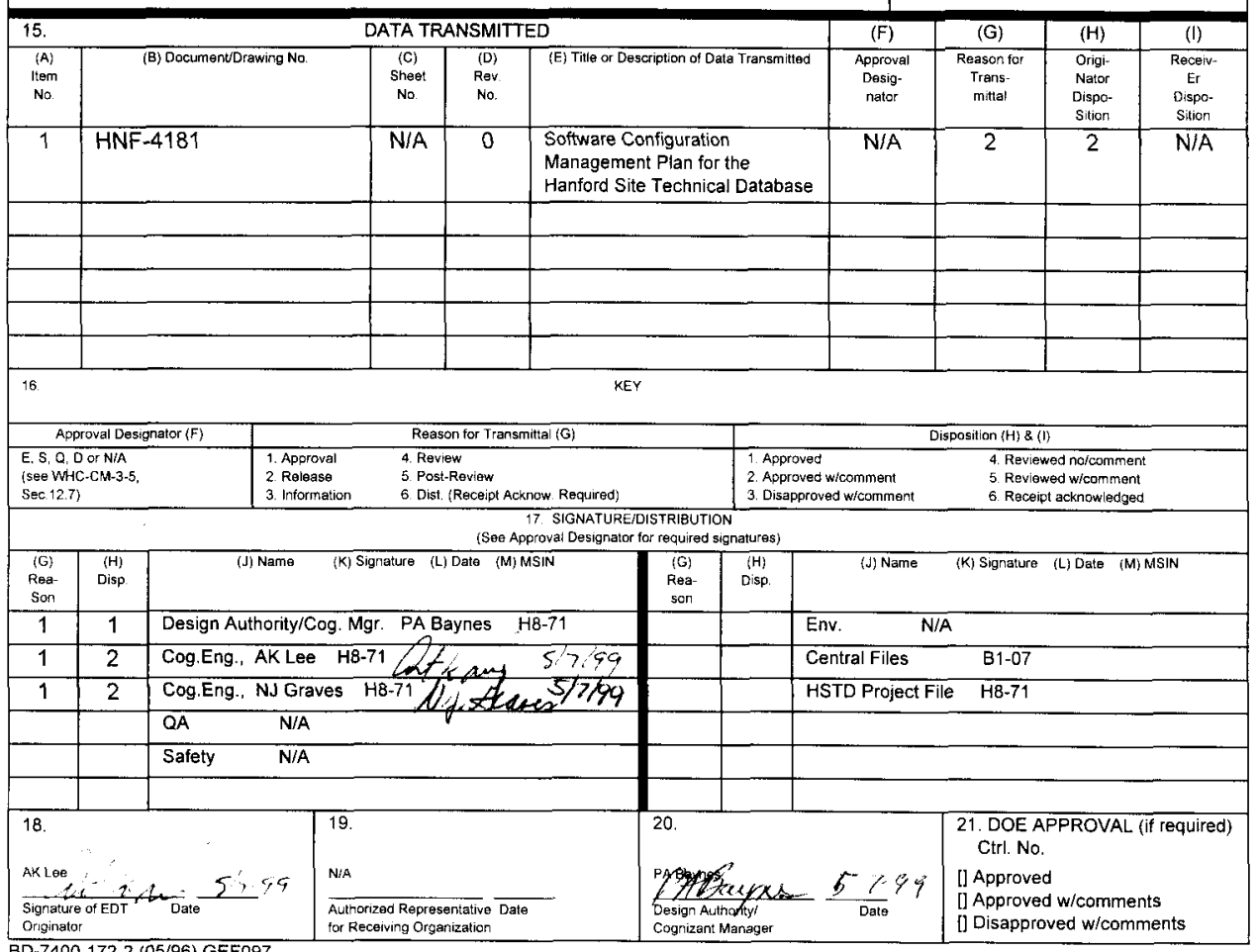




\title{
Software Configuration Management Plan
}

\section{For The Hanford Site Technical Database}

\section{N. J. Graves}

A. K. Lee

Lockheed Martin Hanford Corp., Richland, WA 99352

U.S. Department of Energy Contract DE-AC06-96RL13200

\author{
EDT/ECN: EDT $626754 \quad$ UC: 2030 \\ Org Code: $76100 \quad$ Charge Code: 106978/AR00 \\ B\&R Code: EW02J123 Total Pages: 22
}

Key Words: Software Configuration Management Plan, Hanford Site Technical Database, Software, Database, Configuration Control.

Abstract: This Software Configuration Management Plan contains the configuration management approach for software upgrades within the Hanford Site Technical Database.

TRADEMARK DISCLAIMER. Reference herein to any specific commercial product, process, or service by trade name, trademark, manufacturer, or otherwise, does not necessarily constitute or imply its endorsement, recommendation, or favoring by the United States. Government or any agency thereof or its contractors or subcontractors.

Printed in the united States of America. To obtain copies of this document, contact: Document Control Services, P.O. Box 950, Mailstop H6-09, Richland WA 99352, Phone (509) $372-2420 ;$ Fax $(509) 376-4989$.

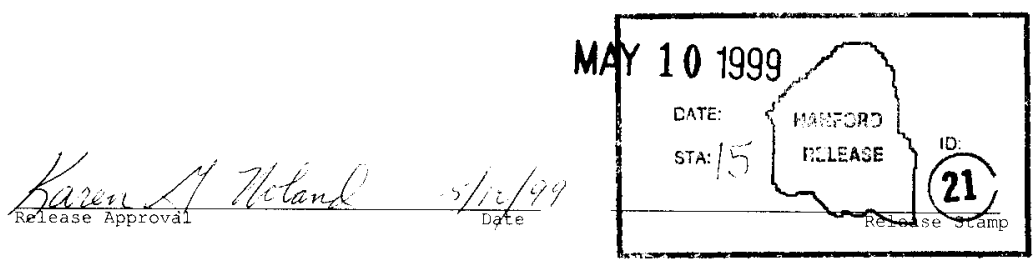

\section{Approved for Public Release}




\section{SOFTWARE CONFIGURATION MANAGEMENT PLAN}

FOR THE

\section{HANFORD SITE TECHNICAL DATABASE}

Prepared for

Lockheed Martin Hanford Company 


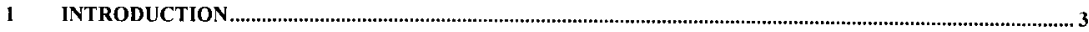

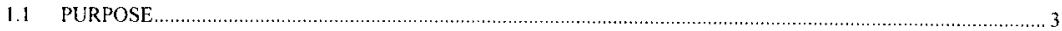

1.2 OVERVIEW

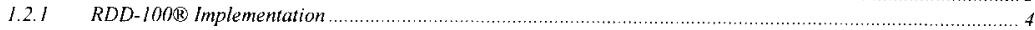

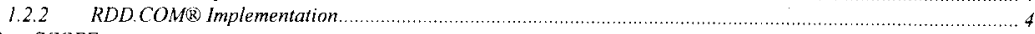

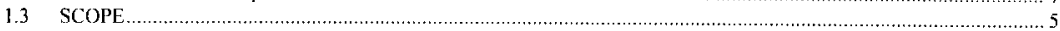

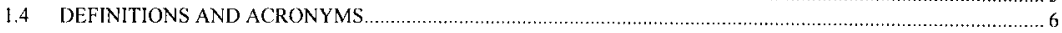

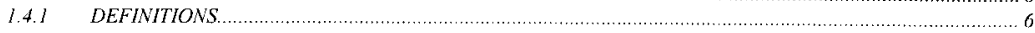

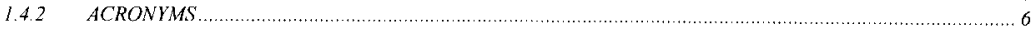

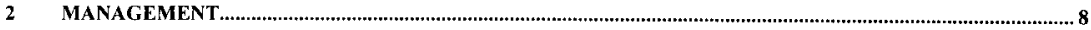

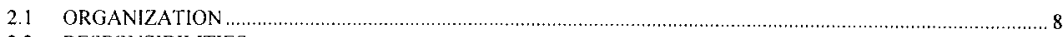

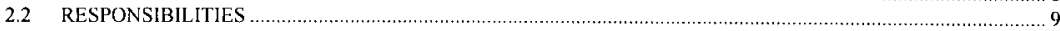

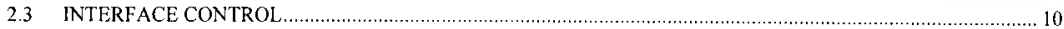

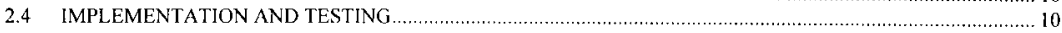

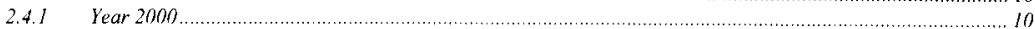

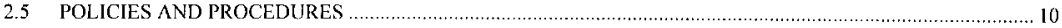

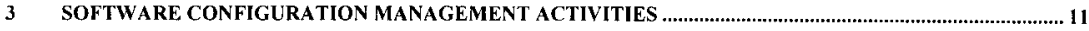

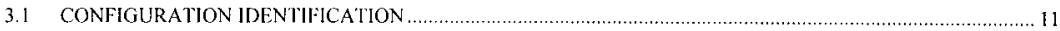

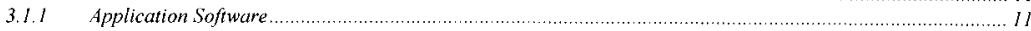

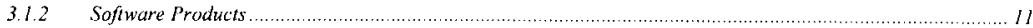

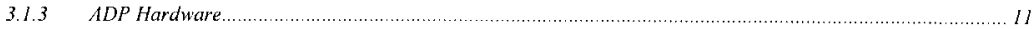

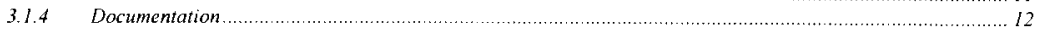

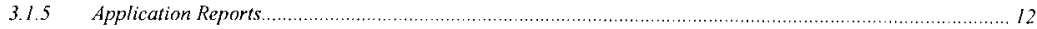

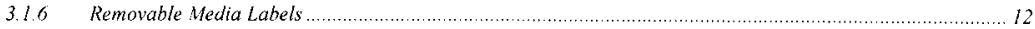

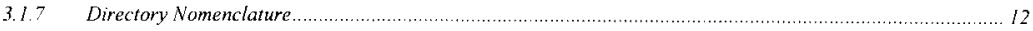

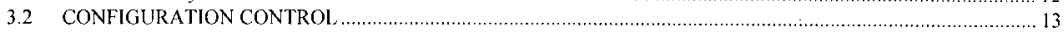

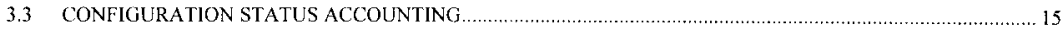

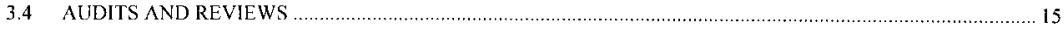

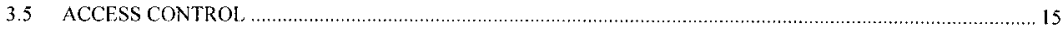

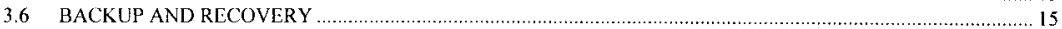

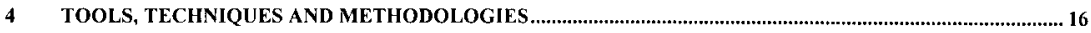

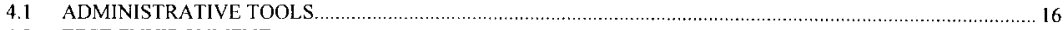

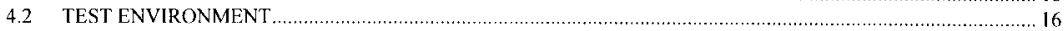

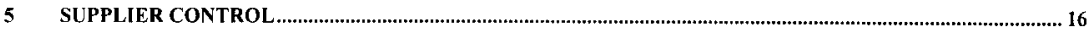

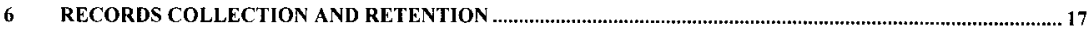

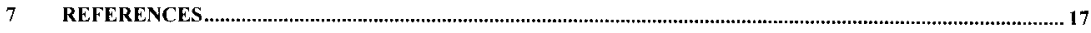

APPENDIX A: HSTD SOFTWARE CHANGE REQUEST AND PROBLEM REPORT FORM .................................... 18

APPENDIX B: HSTD RELEASE COVER SHEET \& REVISION RECORD ......................................................... 19

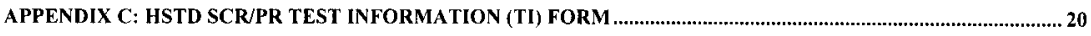

FIGURE 1: SOFTWARE CONFIGURATION MANAGEMENT FLOW CHART FOR THE HSTD ....................14 
The Hanford Site Technical Database (HSTD) is used as the repository/source for the technical requirements baseline and programmatic data input via the Hanford Site and major Hanford Project Systems Engineering (SE) activities. The Hanford Site SE effort has created an integrated technical baseline for the Hanford Site that supports SE processes at the Site and project levels which is captured in the HSTD.

The HSTD has been implemented in Ascent Logic Corporation (ALC) Commercial OffThe-Shelf (COTS) package referred to as the Requirements Driven Design (RDD) software. This Software Configuration Management Plan (SCMP) provides a process and means to control and manage software upgrades to the HSTD system.

\subsection{PURPOSE}

This SCMP provides the software change control process request and implementation by the HSTD System Administrator and other software configuration management activities and responsibilities of the HSTD system. Specifically identified are requirements and responsibilities of the database upgrades and maintenance personnel, the change control process, and how necessary documentation will be updated for each upgrade.

\subsection{OVERVIEW}

Site Systems Engineering, in accordance with the Project Hanford Management Contractor (PHMC), and in accordance with RLID 430.1, is responsible for producing and maintaining a Hanford Site Technical Database. This technical data covers the Environmental Management technical work performed in the Hanford Site. It is developed by Site Systems Engineering and the Projects and is supported by the tools and methods used by systems engineers. Data residing in the HSTD is used to validate the site cleanup system, identify technical issues for resolution where problems exists in the HSTD data and to drive the project's work planning process.

The software tool used to maintain the HSTD is the RDD (i.e., (1) RDD-100 $₫$ ) software tool set developed by ALC. The current RDD version is 4.1.1 with migration underway to a new

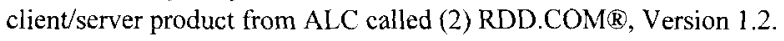

1 RDD-100 is a registered trademark of Ascent Logic Corporation.

2 RDD.COM is a registered trademark of Ascent Logic Corporation. 


\subsubsection{RDD-100® Implementation}

The RDD-100@ implementation, currently in use for the HSTD, consists of electronic files that are shared to HSTD users. The implementation does not support a single data repository that users can access concurrently. The "released-for-use" baseline file, at a given point in time, is contained in one electronic file that is stored on a network server. Users obtain a copy of the electronic file and use the RDD-100ß software to make updates. Those updates are then transmitted back to the HSTD System Administrator for incorporation into a future, new "released-for-use" baseline file.

A (3) Microsoft Windows ${ }^{\mathrm{TM}}$ NT 4.0 workstation contains the license manager software and the current license file. A network server is used to store all the historical electronic baseline files. User access controls are established at the directory level to guard against unauthorized changes. Each client workstation, running either Microsoft Windows ${ }^{\mathrm{TM}}$ 95/98 or Microsoft Windows ${ }^{\mathrm{TM}} \mathrm{NT}$, contains the RDD-100® software.

\subsubsection{RDD.COM® Implementation}

The RDD.COMß software implements a client-server environment. A central data repository contains the production module that manages information for data input and retrieval.

The RDD.COM( $(\mathbb{R}$ system architecture consists of one file server with Microsoft Windows ${ }^{\mathrm{TM}}$ NT 4.0 as the Operating System $(\mathrm{O} / \mathrm{S})$. The file server contains the server software, client software, license manager software, current license file, and data repository. There are approximately 50 client workstations, running either Microsoft Windows ${ }^{\mathrm{TM}} 95 / 98$ or Microsoft Windows ${ }^{\mathrm{TM}} \mathrm{NT}$, that contain the client software. The RDD.COMß system will process the data between the client workstations and server and provide for data retrieval from the client workstations.

The Microsoft Windows ${ }^{\text {TM }}$ NT has the ability to simultaneously process data and allows the server to maintain productivity at a rate consistent with data retrieval demands. The server can have one or many multiple concurrent users, who may need to update the database throughout the workday. The client-server environment will provide the ability to have multiple users concurrently update the server database tables.

3 Microsoft Windows is a trade name of the Microsoft Corporation. 
The primary boundary for the HSTD system is the SE functional domain. The HSTD system is used to assist the SE group with the following activities:

- Requirements Analysis

- Functional Analysis and Decomposition

- Allocation of Requirements to Function and Components

- Development of System Architectures

- Waste/Infrastructure Forecasting

These activities directly support the production and maintenance of the technical baseline. The associated HSTD design basis documentation is provided in the Hanford Site Technical Database \& Software Requirements Document, HNF-SD-WM-SDR-014, Rev. 0. Due to software upgrades, any changes to design basis documentation will be revised via an Engineering Change Notice (ECN). For each software upgrade an evaluation of the HSTD System impact will be required per this SCMP.

This SCMP applies to the HSTD system production version of RDD. The HSTD becomes "production" after the software upgrade has been installed and testing has been performed. Whenever a system test exception or problem occurs it is identified. HSTD system development and maintenance personnel use this SCMP.

This SCMP does not apply to the development and release of the COTS RDD software package developed by the ALC. Also, this SCMP does not apply directly to external systems that may interface with the HSTD system.

This SCMP does not apply to reports and data generated by the HSTD system except when specifically identified. Control of information produced by the software, after it has been exported, is the responsibility of the receiving organization. However, HSTD data sources are the "official" data.

The following documents address the boundaries or scope of configuration management relating to the HSTD:

- The Change Control, HNF-PRO-533, Rev. 0, addresses the change control for baseline management processes.

- The Hanford Site Technical Baseline Change Control, HNF-MD-029, Rev. 1, addresses the data change control process request for an end user. 
- The Data Configuration Management for the Hanford Site Technical Database, HNF-4180, Rev. A (Draft), addresses the data change control process implementation by the HSTD System Administrator and other data management activities and responsibilities.

- This document, the Software Configuration Management Plan for the Hanford Site Technical Database, addresses the software change control process request and implementation by the HSTD System Administrator and other software configuration management activities and responsibilities.

\subsection{DEFINITIONS AND ACRONYMS}

\subsubsection{DEFINITIONS}

Client/Server: Description of a distributed computing environment where the computing load is distributed to varying degrees between the workstation (client) and the Relational Database Management System (server).

Production: A module that has been released for system use following acceptance by the customer.

\section{System Change Request and Problem Report (SCR/PR):}

A form that identifies a proposed change to, or a suspected problem with the HSTD system. An SCR/PR may identify a new function, modify an existing function, or report suspected problems of the software or system hardware, at varying levels of priority.

Software Configuration Management ( $\mathrm{SCM}$ ):

A set of management disciplines within the context of the software engineering process that applies technical and administrative direction and surveillance. It identifies and documents the functional and physical characteristics of a product, controls changes to those characteristics, and it records and reports the change processing and implementation.

\subsubsection{ACRONYMS}

ALC Ascent Logic Corporation

ADP Automatic Data Processing

ATP Acceptance Test Procedure

CCB Change Control Board

COTS Commercial Off-The-Shelf 
HSTD Software Configuration Management Plan

Rev. 0

$\mathrm{ECN}$

Engineering Change Notice

FDH

Fluor Daniel Hanford, Inc.

HSTD Hanford Site Technical Database

LMHC Lockheed Martin Hanford Company

$\mathrm{O} / \mathrm{S}$

Operating System

OTP

Operational Test Procedure

PHMC

Project Hanford Management Contractor

RDD

Requirements Driven Design

$\mathrm{SCM}$

Software Configuration Management

SCR/PR System Change Request and Problem Report

$\mathrm{SE}$

Systems Engineering

$\mathrm{SI}$

Systems Integration

SSE

TI

Site Systems Engineering

QA Test Information Form

$\mathrm{V} \& \mathrm{~V}$

Quality Assurance

Y2K

Validation and Verification

Year 2000 


\section{MANAGEMENT}

\subsection{ORGANIZATION}

LMHC, Site Systems Engineering (SSE) is designated as the system/software owner. The LMHC SSE identified the need for the HSTD. The LMHC SSE is responsible for maintaining database integrity and control.

The specific group within the LMHC SSE affected by this plan is the LMHC Systems Integration (SI) group. The interfaces between these organizations are through normal line management chain of command.

LMHC, Systems Integration is assigned the responsibility to continue appropriate software upgrades and testing of the system. The LMHC SI is also the custodian and maintenance authority of the HSTD. This group maintains information in a HSTD project file. They are responsible for the issuance, maintenance, and change authority of this SCMP.

HSTD Users are designated as liaisons of their Project in order to provide and input their Project's functional requirements and technical baseline data into the HSTD. The LMHC SSE coordinates and monitors the user's requests for system problems. Users are those individuals and organizations who input or need information from the HSTD and having both a need-toknow and the proper training and authority to access. Each user or user organization is required to comply with the established requirements and procedures governing the HSTD. At this time, LMHC SSE is currently working with the prime contractors from the PHMC.

The RDD software was developed by Ascent Logic Corporation. Ascent Logic Corporation configuration management practices are not included in this SCMP. 


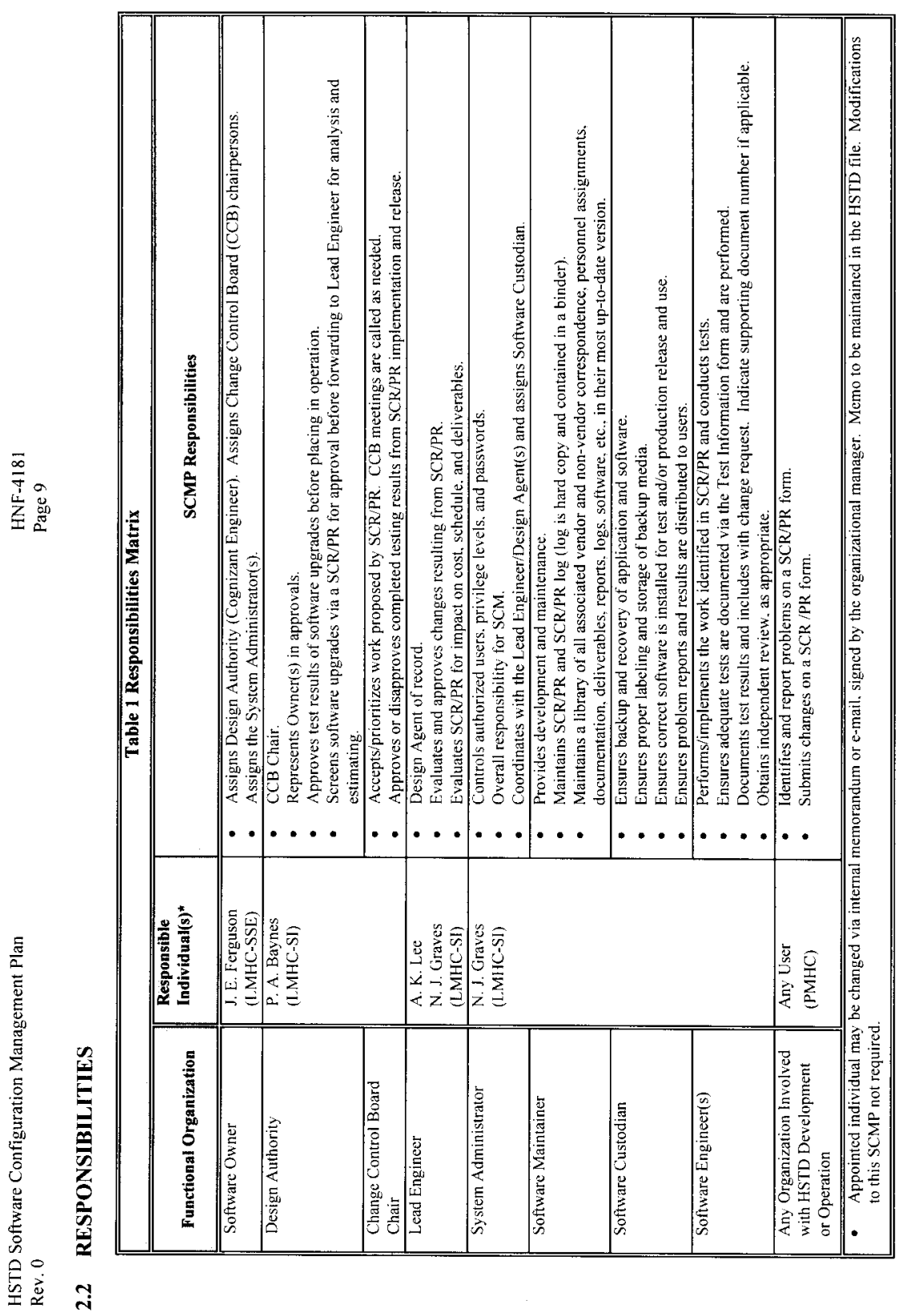




\subsection{INTERFACE CONTROL}

This SCMP is the only control mechanism to be used for the HSTD system software upgrades, except in cases where the ECN process is designated for system documentation.

The Change Control Authority is via a Change Control Board that is appointed by the LMHC SI CCB Chair designated in Table 1. The CCB roles and responsibilities are per this SCMP.

\subsection{IMPLEMENTATION AND TESTING}

This SCMP becomes effective, for the HSTD production system, whenever a system problem or change request is identified or when a software upgrade is to be integrated into the baseline system as a production module.

Ascent Logic Corporation is responsible for the version change control of the RDD source code and executables. However, appropriate testing may become effective when: 1) RDD major revisions are released for integration testing and \or major issues, and 2) minor revisions when released for production changes. To aid in determining the type of testing that is appropriate for the software upgrade, a "SCR/PR Test Information (TI) form" is used (see Appendix C). The SCR/PR TI form ensures that the topics generally outlined in a test plan are considered when determining what level of testing is necessary for the software upgrade.

\subsubsection{Year 2000}

Although, the version 4.1.1, RDD software is COTS, it was still tested in accordance with Fluor Daniel Hanford's Year 2000 (Y2K) testing criteria. It is assumed that any future versions of the RDD software have been tested appropriately by ALC. In the event ALC provides software with $\mathrm{Y} 2 \mathrm{~K}$ issues, a mechanism to capture any $\mathrm{Y} 2 \mathrm{~K}$ issues has been identified on the SCR/PR form that, once completed, can be forwarded to the ALC.

\subsection{POLICIES AND PROCEDURES}

Software configuration management of HSTD will be in accordance with HNF-PRO2778, IRM Application Software System Life Cycle Standards particularly with regard to $\mathrm{SCR} / \mathrm{PR}$ and document approvals. 


\section{SOFTWARE CONFIGURATION MANAGEMENT ACTIVITIES}

\subsection{CONFIGURATION IDENTIFICATION}

\subsubsection{Application Software}

Associated design basis documentation that establishes the foundation for the configuration of the HSTD system description is currently in the Hanford Site Technical Database \& Software Requirements Document. HNF-SD-WM-SDR-014, Rev. 0 and Ascent Logic Corporation's RDD technical manuals provided with each upgrade.

Each production software upgrade shall be a grouping of the code and executable software products, and any modifications to vendor software (e.g., configurations, etc.) as specified by Ascent Logic Corporation. The Ascent Logic Corporation assigns the release.

The software identification will be as per Ascent Logic Corporation's software version naming conventions. At a minimum, Ascent Logic Corporation provides each version of the RDD software with a version identification number.

A designator will also be used to designate the testing phase (Acceptance Test Procedure or ATP for acceptance testing, Operational Test Procedure or OTP for operational testing, or SYS for an operational system). Refer to the sample form in the "Release Cover Sheet and Revision Record," Appendix B. The release form shall also note operating system and development tool revision numbers in Section 7 of this same form.

\subsubsection{Software Products}

Each software product (e.g., the application software development packages, the $\mathrm{O} / \mathrm{S}$ software, the network communications software, etc.) is assigned a unique product name and release version number. This product name and version number will be used as identification as much as practical on the software release documentation (Appendix B).

\subsubsection{ADP Hardware}

The ADP hardware for the HSTD system is identified by vendor brand name and model number and by specifications that the equipment must meet. At the Hanford Site, specific equipment is identified by a procurement control number affixed by the Procurement Group upon receipt of the equipment onsite. Procurement for the ADP hardware for the HSTD is controlled by Hanford procedures. 
HSTD Software Configuration Management Plan

HNF-4181

Rev. 0

Page 12

The LMHC SI controls location of the computer hardware. Configuration control is required by the HSTD SCMP in the following cases: 1 ) identification of the minimum equipment necessary for operation, and 2) evaluation of impact caused by interface hardware changes that are part of the design basis documentation set via an SCR/PR.

\subsubsection{Documentation}

Each HSTD system document is assigned a unique name, number, and revision in accordance with the HNF documentation procedures and are documented in Appendix B, "Release Cover Sheet and Revision Record". See Appendix B, Section 6 for a sample listing.

The Software Maintainer shall keep and maintain the HSTD SCR/PR forms in a log in local project files. When a release of a revised HSTD system occurs, the Software Maintainer will either: 1) establish a file with the information related to that release, or 2) produce an HNF document to formally document the release sheet and associated SCR/PRs.

\subsubsection{Application Reports}

Control of application reports generated by the HSTD system is not provided under this SCMP, and is the responsibility of the software end user organizations.

\subsubsection{Removable Media Labels}

The HSTD master media is labeled per Ascent Logic Corporation's naming convention. The master media includes the CD-ROM with loaded (RDD) software, floppy disk with licensing agreement files, and a dongle license key. The baseline system naming conventions and backup media of data files are discussed in Data Configuration Management for the Hanford Site Technical Database, HNF-4180, Rev. A (Draft).

\subsubsection{Directory Nomenclature}

Original source and executable software placed on media containing multiple versions/revisions shall be segregated using the available directory/subdirectory structure. Current directory structures are located in the HSTD project files.

A major directory shall be provided for the software product, labeled with the ALC's product mnemonic. ALC controls the directory name and structure for each release. 


\subsection{CONFIGURATION CONTROL}

All HSTD system change control originates with SCR/PR forms that are filled out and submitted by HSTD end-users. The process flow diagram for implementing potential changes to the baseline HSTD system, including organizational responsibilities, is provided in Figure I. See Appendix A for an example of the SCR/PR form.

Email approvals for processing SCR/PR form may be substituted for handwritten approvals. When e:mail approvals are used, a copy of the e:mail approval must be attached to the SCR/PR. Telephone approvals for processing SCR/PR form may be used, but must be documented on the SCR/PR form or with an e:mail approval.

Revisions to the HSTD system documentation are processed in accordance with HNF-PRO-244, Engineering Data Transmittal Requirements and HNF-PRO-440, Engineering Document Change Control Requirements. These procedures are also used to process the transmittal of the "Release Cover Sheet and Revision Record" to document a change in baseline per the SCR/PRs implemented. See Appendix B, Section 6 for a sample listing. 


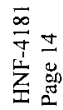

.
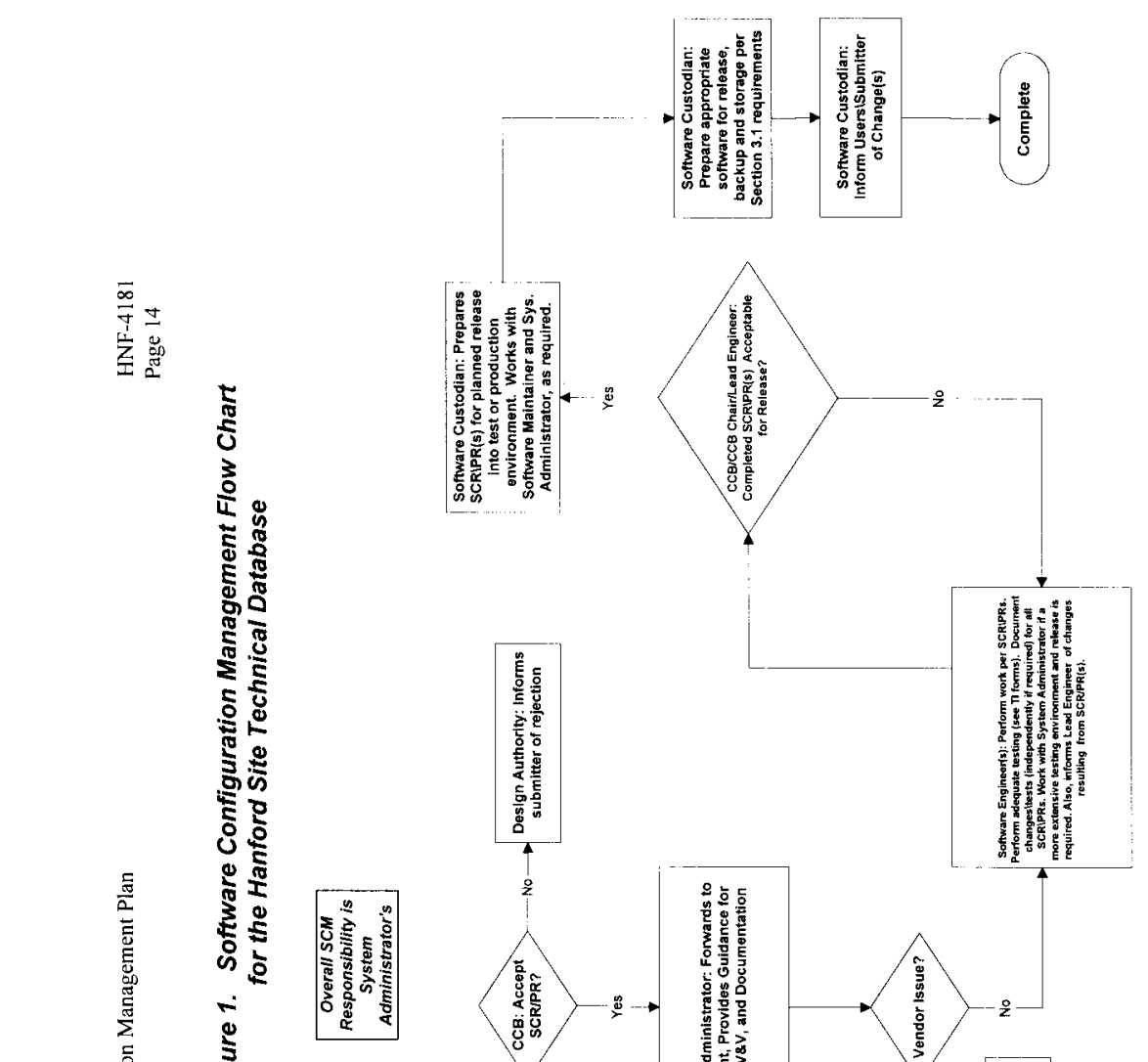

E⿱

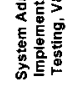

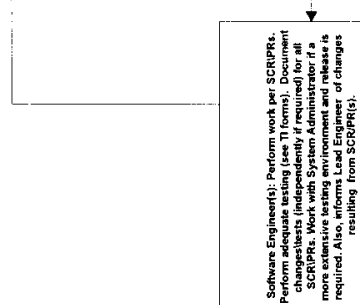




\subsection{CONFIGURATION STATUS ACCOUNTING}

The configuration status of all controlled items is shown on the "Release Cover Sheet and Revision Record" (Appendix B). In addition, the status of all SCR/PRs and associated releases will be maintained and available in the HSTD SCR/PR logbook, available from the Software Maintainer.

\subsection{AUDITS AND REVIEWS}

The HSTD and associated documentation, including software change control, will be available for audit during established LMHC business hours. The System Administrator should periodically audit the project file and change control documentation to ensure compliance. Other surveillance and audits are the responsibility of outside organizations and are outside the scope of this SCMP.

All changes and tests shall be reviewed and verified. For minor changes and releases, test results may be attached to the SCR/PR.

Should changes require major modifications or enhancements, the Lead Engineer, Software Engineer and Design Authority will determine if a formal plan will be prepared. The formal plan will identify appropriate technical, Validation \& Verification (V\&V) and Quality Assurance $(\mathrm{QA})$ reviews consistent with HNF procedures and commensurate with the complexity of the change.

\subsection{ACCESS CONTROL}

Access control for operation of the HSTD software is provided by the application. It provides for an authorized user list and associated privilege levels. Authorized users are required to provide a user name and password. Authorized users and passwords for access will be assigned and controlled by the System Administrator. The System Administrator will authorize access only after appropriate training is provided. Basic RDD training is to be provided by the ALC. The HSTD software is protected to restrict those with access from altering the database functions inadvertently. 


\subsection{BACKUP AND RECOVERY}

Backup of the source code and executable files that constitute each product release is done with support from Ascent Logic Corporation. The Software Custodian is responsible for the data, but not recovery of the source code and executable files. Back up media is via Ascent Logic Corporation's master media CD-ROM with loaded (RDD) software. The Software Custodian is responsible for verifying that the backup is in place and the appropriate data files exist.

Recovery shall be accomplished by reloading appropriate files from the master media onto the production fileserver or its replacement. This shall be accomplished by the Software Custodian or Lead Engineer'Software Engineer as needed. Should the master media be simultaneously corrupted, a replacement master media shall be provided from Ascent Logic Corporation.

\section{TOOLS, TECHNIQUES AND METHODOLOGIES}

\subsection{ADMINISTRATIVE TOOLS}

HSTD administration tools for implementation of this SCMP include the Responsibilities Matrix (Table 1), SCR/PR Flow Chart (Figure 1), SCR/PR form (Appendix A) and log, and Release Cover Sheet \& Revision Record (Appendix B).

Software and hardware tools and training are outside the scope of this SCMP, but it is assumed that adequately trained personnel will invoke approved and appropriate system changes.

\subsection{TEST ENVIRONMENT}

All HSTD hardware and software upgrades will be installed and certified in a test environment where possible and separated from production. These changes will be implemented into the production environment only after the Design Authority has reviewed and approved the test results and the CCB has approved the implementation. The "SCR/PR Test Information form" (Appendix C) allows the HSTD System Administrator to identify test procedures as necessary. See section 2.4. 


\section{SUPPLIER CONTROL}

The Software Engineer will ensure that new releases and installation of the vendor application and software product are tested prior to its being placed in production. Changes in vendor application and/or software product will be processed as a change request or problem report with the same approval requirements as a locally generated change.

The Software Maintainer will maintain a project file, binder or index of all vendorprovided materials, manuals, project documentation, correspondence, and project documents. This project file, binder or index will be maintained for use by all HSTD personnel, as required, for the life of the HSTD.

\section{RECORDS COLLECTION AND RETENTION}

The HSTD Software Maintainer will process software maintenance records in accordance with HNF-PRO-2778, IRM Application Software System Life Cycle Standards. Any items indicating "Forward to Records Management..." will instead be sent to the System Administrator. These records, at a minimum, include the SCR/PR logbook and SCR/PR form entries, and will be kept by the Software Maintainer in local project files. 
HSTD Software Configuration Management Plan

HNF-4181

Rev. 0

Page 18

\section{REFERENCES}

Change Control, HNF-PRO-533, Rev. 0, Fluor Daniel Hanford, Richland, Washington.

Engineering Data Transmittal Requirements, HNF-PRO-244, Fluor Daniel Hanford, Richland, Washington.

Engineering Document Change Control Requirements, HNF-PRO-440, Fluor Daniel Hanford, Richland, Washington.

Hanford Site Technical Baseline Change Control, HNF-MD-029, Rev. 1, Fluor Daniel Hanford, Richland, Washington.

Data Configuration Management for the Hanford Site Technical Database, HNF-4180, Rev. A (Draft), Lockheed Martin Hanford Company, Richland, Washington.

Hanford Site Technical Database \& Software Requirements Document, HNF-SD-WMSDR-014, Rev. 0, Lockheed Martin Hanford Company, Richland, Washington.

IRM Application Software System Life C'ycle Standards, HNF-PRO-2778, Fluor Daniel Hanford, Richland, Washington. 
HSTD Software Configuration Management Plan

HNF-4181

Rev. 0

Page 19

\section{APPENDIX A: HSTD SOFTWARE CHANGE REQUEST AND PROBLEM REPORT FORM}

Any user may fill out a "Software Change Request" (SCR) and Problem Report form describing a change or problem (see form below). The form should be sent to the appropriate individual at MSIN R1-19. This individual will log this form and track resolution.

\section{SOFTWARE CHANGE REQUEST AND PROBLEM REPORT [SCR/PB] FORM}

NOTE: User Fills In Parts 1-8 (NON-GRAY)

1. SCR: [ ] Upgrade [ ] Problem (submit to Vendor) [ ] Y2K

2. Requested Completion Date:

3. Submitted By:

4. Software Program Name:

5. Submitter's Priority [ ]

(1= Critical $2=$ Important $3=$ Low Priority)

6. Task/Change/Problem Title (One Sentence Description):

7. Detailed Description/Justification (Attach Additional Sheet If Necessary):

FOR HSTD CHANGE CONTROL BOARD USE ONLY:

Decision: [] Accept [] Modify [ ] Reject [] Defer

Assigned To:

Is Testing Necessary? [ ] Yes [ ] No

(Complete SCR/PR TI form if necessary)

Target Release Date:

Suggested Solution Comments \& Impact Evaluation:

Software Programs, Modules or Files Affected (Attach Testing Sheets As Required):

\begin{tabular}{|l|l|}
\hline Task Completed By: & Date: \\
\hline Verified By: & Date: \\
\hline Actual Release Version: & Date: \\
\hline Closed By: & Date: \\
\hline
\end{tabular}


HSTD Software Configuration Management Plan

HNF -4181

Rev. 0

Page 20

APPENDIX B: HSTD RELEASE COVER SHEET \& REVISION RECORD

RELEASE COVER SHEFT \& REVISION REEORI

1. Software ID (Name):

2. Release Type: [ ] Initial Release [ ] Change

Rev:

3. Abstract

4. Software Files (or attach directory listing)

5. Software files record storage media and location

\begin{tabular}{|c|c|c|c|}
\hline 6. Documentation & Title & Number & Rev \\
\hline \multicolumn{4}{|l|}{ Design } \\
\hline \multicolumn{4}{|l|}{ Design Verif. } \\
\hline \multicolumn{4}{|l|}{ Validation } \\
\hline \multicolumn{4}{|c|}{ User } \\
\hline \multicolumn{4}{|l|}{ Config. Cntl. } \\
\hline 7. Environment & Description & Rev & IL/Sfty Class \\
\hline \multicolumn{4}{|l|}{ Hardware } \\
\hline \multicolumn{4}{|l|}{ Oper. Software(s) } \\
\hline Language(s) & & & \\
\hline Comm. Networks & & & \\
\hline
\end{tabular}

8. Released for:

[ ] Integration [ ] Acceptance Test [ ] Operational Test [ ] Operation

9. Approvals:

Lead Engineer

Date:

Design Authority:

Date:

System Administrator:

Date: 
HSTD Software Configuration Management Plan

HNF-4181

Rev. 0

Page 21

\section{APPENDIX C: HSTD SCR/PR TEST INFORMATION (TI) FORM}

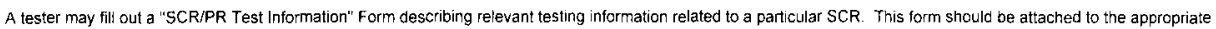

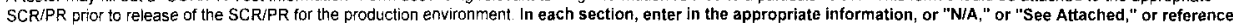
another document by number.

\section{SCR/PR IEST LFFORMATION CTD FORM}

\section{TO BE COMPLETED BY THE HSTD SCMP DESIGNATES PER HNF-4181}
1. Related SCR/PR Number(s)
2. Type of Maintenance
[ ] Upgrade [ ] Problem [ ] Y $2 \mathrm{~K}$

IFA SEPARATE TEST PROCEDURE AND ASSOCIATED DOCUMENTATION WAS DEVEL OPED FOR THIS SCR/PR FILL OUT APPLICABLE HNF REFERENCE NUMBER(S) IN THIS SPACE AND DO NOT FHLL OUT THE REMAINDER OF THIS FORM:

\subsection{TEST PLAN \\ 1.1 Test Items:}

1.2 Features to Test/Not Test:

1.3 Deliverables:

1.5 Testing Tasks:

1.7 Responsibilities:

1.9 Schedule:

2.0 TEST DESIGN requires (attach if checked): [ ] Readiness Review [ ] Training Review [ ] Safety Review
1.4 Acceptance Criteria:

1.6 Environmental Needs:

1.8 Staffing and Training:

1.10 Risks and Contingencies:

[ ] Independent Testing [ ] Independent Reviewer

2.1 Approach:

2.2 Pass/Fail Criteria:

3.0 TEST CASES [ ] N/A [ ] See Attached [ ] Reference:

Note: Ensure That Incident Report(s) are Generated and Retest Criteria are Addressed if any Test Case(s) Fails.

\subsection{TEST PROCEDURES [ ] N/A [ ] See Attached [ ] Reference:}

\subsection{TEST ITEM TRANSMITTAL REPORT}




\section{DISTRIBUTION SHEET}

\begin{tabular}{|c|c|c|c|c|c|}
\hline \multirow{2}{*}{$\begin{array}{l}\text { To } \\
\text { Distribution }\end{array}$} & \multirow{2}{*}{\multicolumn{3}{|c|}{$\begin{array}{l}\text { From } \\
\text { Site Systems Engineering/Systems } \\
\text { Integration }\end{array}$}} & \multicolumn{2}{|l|}{ Page 1 of 1} \\
\hline & & & & \multicolumn{2}{|c|}{ Date May 6, 1999} \\
\hline \multicolumn{4}{|l|}{ Project Title $N$ Work Order } & \multicolumn{2}{|c|}{ EDT No. 626754} \\
\hline \multicolumn{4}{|c|}{ Software Configuration Management Plan for the Hanford Site Technical Database } & ECN No. N/ & \\
\hline Name & MSIN & $\begin{array}{l}\text { Text } \\
\text { With All } \\
\text { Attach. }\end{array}$ & $\begin{array}{l}\text { Text } \\
\text { Only }\end{array}$ & $\begin{array}{l}\text { Attach./ } \\
\text { Appendix } \\
\text { Only }\end{array}$ & $\begin{array}{c}\text { EDT/ECN } \\
\text { Only }\end{array}$ \\
\hline Central Files & $\mathrm{B} 1-07$ & $x$ & & & \\
\hline $\begin{array}{l}\text { P. A. Baynes } \\
\text { J. E. Ferguson } \\
\text { N. J. Graves } \\
\text { M. L. Grygiel } \\
\text { A. K. Lee } \\
\text { B. L. Worthington } \\
\text { HSTD Project File } \\
\text { RL Reading Room }\end{array}$ & $\begin{array}{l}\text { H8-71 } \\
\text { H8-71 } \\
\text { H8-71 } \\
\text { H8-71 } \\
\text { H8-71 } \\
\text { H8-71 } \\
\text { H8-71 } \\
\text { H2-53 }\end{array}$ & $\begin{array}{l}x \\
x \\
x \\
x \\
x \\
x \\
x \\
x\end{array}$ & & & \\
\hline
\end{tabular}

